and it is therefore of greater importance that a sailor or engine-driver should be able to perceive them. The third class contains persons who are able to distinguish colours easily when they are close to, but fail to distinguish them at a distance owing to the nerve fibres supplying the central portion of the retina being impaired. As a light at a distance occupies the central portion of the visual field it is essential that the corresponding portion of the retina should be normal. There are cases of central scotoma for colours with perfect form vision; these would, therefore, not be detected by the test for visual acuity. This class also includes those who, without having a scotoma, are unable to distinguish between colours at the normal distance when the image on the retine is diminished in size.

The lantern shown has been constructed conformably with the requirements and facts of colour blindness. All the facts of colour blindness have been considered in constructing the lantern.

Objections to other Tests for Colour Blindness.

The tests which have been proposed for colour blindness are very.numerous, but some are so defective that it is rare to detect a single colour-blind person with them. I have, for instance, tested men whom I knew to be colour blind with certain lanterns, with the result that not a single one was detected. In these so-called tests all the requirements of a test and facts of colour blindness have been neglected. I must, however, refer to three tests constructed by excep. tionally able men, each with considerable knowledge of the subject. I refer to the tests of Professor Holmgren, Professor Stilling, and Professor Nagel.

All these tests can be passed at the first attempt and without coaching by certain dangerously colour.blind persons, chiefly varieties not known to the inventors; bat the chiel defect of each is that it is very easy to coach a colour-blind person to pass it. The surgeon to one of our largest railway companies told me that when they used Holmgren's test they rejected 1 man in 300 , but with my lantern 12 in the same number. All these three tests are much better tests when the persons to be examined have not seen them before. A colour-blind man may make only one mistake; say, for instance, as in a case I examined the other day with Nagel's test (last edition), he passes the test perfectly with the exception of one mistake, that of calling a grey on one card, green. All he has to do is to look for some distinguishing mark on this card in order to go through the test with the ease and certainty of a normal-sighted person. It is the same with Stilling's letters, he has only to note the letter which he was not able to read and the appearance of the card. A normal-sighted man or woman would readily help him. The confusion of green and grey does not appeal to the average man as a serious defect especially when he sees his friend go through the rest of the test perfectly. He says to himself, "I suppose he sees a tinge of green in that grey."

The same man would rightly regard it as a most iniquitous proceeding to endeavour to corch his friend through a test when he had seen him mistake a red for a green light.

Holmgren's test rejects a large number of normalsighted persons, as may be seen by the reports of the Board of Trade; about 50 per cent. of those who appeal arefound to be normal sighted and to have been rejected wrongly.

$$
\text { REFERENCES. }
$$

1 Journ. of Physiol., vol. xli, p. 274. ${ }^{2}$ Trans. Ophth. Soc., 1902, p. 300 3 Journ. of Physiol., vol, xli, p. 269. 1 BRITIsH MEdICAL JouRnaL, 1910 p. 556. S Journ. of Physiol.. xli, p. 266. ' Nagel, Physiol. des Menschen. vol. iii, p. 107.

THE French Medical Parliamentary Group, among its other activities, watches over the interests of the thermal and climatic stations of France. It has decided to take steps to secure speedy promulgation of the Governmental decree imposing a "cure tax" on visitors. It is hoped that this will be put into force during the coming season and that in this way funds will be collected in sufficient amount to enable improvements to be made that will attract foreigners. It has also been decided to found a chair for the instruction in hydrology and climatology in the University of Paris. It appears that the syndicates of the various spas are quite willing to bear the expense on the understanding that the chair is established solely in the general interests of the country.

\section{THE HISTORY OF YELLOW FEVER IN WEST AFRICA.}

SIR RUBERT BOYCE, F.R.S.,

PROFESSOR OF PATHOLOGY, LIVERPOOL ONIVERSITY. (Concluded from page 250.)

VII.

HISTORY OF YELLOW FEVER IN THE GOLD COAST COLONY.

There can be little doubt that yellow fever was as prevalent on the Gold Coast in the early part of the nineteenth century as in Sierra Leone.

From the report of Staff Surgeon Tidlie, quoted by Boyle, it appears that in 1819, out of 9 new arrivals, 3 died; in 1820, out of 4 new arrivals, 2 died; and in 1821 , out of 7 new arrivals, 2 died, or two-thirds of all newcomers within twelve months of arrival. In the same period 15 of the Atrican Company had died. It is most probable that this fatal disease which attacked the newcomers was here, as elsewhere in the tropics, yellow fever.

In a report by Bell, upon the garrison at Cape Coast Castle for 1824, it is stated that 217 deaths occurred in the regiments, exclusive of women and children.

Of the first detachment of Europeans, numbering 128, which arrived in April, 1823, only 1 survived; out of 109 women and children who had arrived aince October, 1823, 70 had died.

It is stated in the report that the cause of death was bilious remittent fever, which usually terminated fatally on the third, fifth, or seventh day. Many of the cases were as "yellow as an orange." Boyle also mentions that an epidemic occurred in 1824, similar to that which took place in Freetown in 1823

In 1824, out of a third detachment of $131 \mathrm{men}$, disembarked in March, 1824, the majority had died, after a few months, from "remittent fever and dysentery," and the same occurred with numerous subsequent detachments. Then comes the usual pause, commencing from the middle of the nineteenth centary, probably due to the withdrawal of the garrison, and therefore of large bodies of nonimmnne new arrivals.

At a later date, following on the commercial development of the colony and the growth of the coast towns, jellow fever again began to attract attention.

As had happened, however, in other British West African colonies, the disease was very frequently not recognized, and was more often wrongly diagnosed.

Examination of the casebooks of the European hospitals in the principal seaports are of very great interest, for they show, in the first place, the difficalties which medical officers experienced in making a diagnosis; and, secondly the unwillingness, as in Sierra Leone, on the part of the medical authority of the colony, to admit that yellow fever existed, in spite of the fact, as the careful records amply testify, of the patients presenting all the classical symptoms of fatal yellow fever. The stumbling-block here, as in numerous other instances, being occasioned by the confusion brought about by the use of the word "con. tagious," as applied to yellow fever.

Examination of the medical reports of the colony show that cases of yellow fever were recorded in the following years: 1895, several cases ; 1897, 4 cases ; 1902, 2 cases.

Whilst on the Gold Coast I examined the hospital casebooks of Capo Coast, Saltpond, Elmina, Axim, and Accra and I find that yellow fever was diagnosed as sach, and entered in the hospital casebooks at Cape Coast in 1897, 1902. and 1903; at Saltpond in 1897 and 1902; at Elmina in 1895; and at Accra in 1899.

In 1899 Dr. Elliott, who had had four years' experience in the Gold Cosst, published in detail 3 cases of yellow fever which he attended at Saltpond.

He alludes to the reluctance prevalent against the diagnosis of yellow fever and the tendency to regard all fevers as malarial.

In 1901 Dr. S. O. Browne published a case of yellow fever which he attended at Saltpond.

In addition to these well-marked cases which were diagnosed at the time by the physicians in charge as 
genuine yellow fever, the bistories of the cases in my opinion also furnish unmistakable proof of the almost continuous occurrence of yellow fever lor the past filteen years.

The evidence is all the more trustworthy, for the medical officers who recorded the symptoms were not looking out for yellow fever.

The histories also show the difficulty which a medical officer experienced in interpreting the symptoms on the supposition that the disease might be malarial fever.

From my analyses of the casebooks, I conclude that yellow fever existed in addition to the above dates in the following places on the coast:

\section{Ermina.}

History of Cases Examined since 1895 up to Date.

In March, 1895, a case was diagnosed as "hepatic fever," and ended fatally.

The symptoms were great prostration, black vomit (coffee-like grounds), eyes and skin yellow, suppression of arine.

In April, 1895, a case diagnosed as " malarial fever." It terminated fatally. The symptoms were: Intense head. ache and backache, nausea and epigastric pain, black vomit, temperature $1034^{\circ}$, pulse 92. A post-mortem examination showed skin yellow, stomach containing black vomit, congestion of the ekin.

The doctor in charge of the case strongly suspected yellow fever in this case, as also in the preceding case.

In Jannary, 1902, a case was diagnosed as "resembling yellow fever." The symptoms were intense headache, albuminuria, intense vomiting, black vomit, black motions, death.

The casebook shows in addition numerous histories of cases which might well have been both mild and severe cases of yellow fever.

\section{Quitra.}

I examined the cases in the casebook from 1888-1900. In 1894 a new arrival was taken ill, and a diagnosis of " malignant remittent fever" was made. Temperature $104^{\circ}$; conjanctiva yellow; vomiting; urine black and bloody; delirium; albuminuria, followed by suppression of urine, convalsions, and death.

The medical officer states:

I cannot help being struck by'the severe and persistent symptoms of this case, particularly the vomiting, which nothing seemed to affect. In fact I can scarcely see the difference between such a case as the above and yellow fever.

In 1900 a suspicious case also occurred, the diagnosis being remittent fever.

The medical officer stated the probability that the patient might be suffering from yellow fever suggested itself; but as the temperature showed no signs of subsid ing, and there was no congestion of the face, it was decided that it would be better to wait and see, than to suggest the possibility to head quarters.

\section{Saltpond.}

Examination of Cases from 1889 to 1903.

In 1895 a case occurred, diagnosed as remittent fever, terminating fatally. It was characterized by jaundice temperature $1058^{\circ}$; pulse 60; black vomit; suppression of urine; hiccough ; intense headache.

There were also about this time numerous other cases with a similar diagnosis presenting very suspicious symptoms.

In 1897 yellow fever was diagnosed.

In July, 1897, a case was diagnosed as haemoglobinuria and acute nephritis.

It was not diagnosed as vellow ferer because of the absence of black vomit. Fagot's sign, jaundice and hiccough, were, however, present, and haemorrhage from gams, as well as vomiting of dark bilious fluid is mentioned.

So, considering there were other cases in that year, it is not improbahle that this was also a case of yellow fever.

In June, 1898 a cese occurred, ending fatally, diagnosed as acute delirous malignant malarial fever.

The patient was so maniacal that be had to be hand. cuffed ; temperature $1054^{\circ}$, and rose to $1072^{\circ}$; skin jaun diced, head and shoulders intensely congested, nausea, vomiting, coma, and death.
Necropsy.-Cataneous haemorrhageg, mucous membrane of stomach intensely congested, stomach contained dark green treacly mass, liver saffron yellow, with patches of congestion. This might well have been a case of yellow fever, in spite of the fact that it is stated "pigmented corpuscles were found in the blood."

In 1901-2 cases were diagnosed as yellow fever, but in addition in each year there occurred cases which, when we know that there were genuine cases of yellow ferer, might equally well have been cases of yellow fever. The diagnoses made were usually " bilious remittent fever."

\section{4. АхIм.}

Examination of Casebooks from 1906 to 1910.

In 1905 the medical officer in charge of a case which occurred in that year at Axim, and which terminated fatally, is now of the opinion that the case was one of yellow fever.

In this year (1910) a death occurred from yellow fever and was reported. The symptoms were, however, not well marked.

Later on in 1910 another fatal case occurred, which was diagnosed as "remittent fever." The chief symptoms were: Temperature $1049^{\circ}$; pulse-rate from 110 to 120 ; temperature did not yield to large doses of quinine.

Another case was diagnosed as "pernicious remittent fever," and proved fatal. The symptoms were intense hesdache; temperature $1028^{\circ}$; pulse 88; delirium, and finally coma. The doctor in charge suspected yellow fever.

\section{Cape Coast.}

In 1903 Dr. G. L. Barker wrote to the acting principal medical officer at Accra reporting a case of yellow fever, and he states that " this makes the fitth case this year."

The medical officer who diagnosed the case was Dr. Rome Hall, and the principal medical officer, in writing a memorandum to the Colonial Secretary, states :

I regret to say that I am obliged to take the alarmist tatement, made by Dr. Rome Hall, with a large amount of doubt.

In 1895 a case of remittent fever is diagnosed, in which the characteristics are congestion, intense headache, tem. perature $1088^{\circ}$, and pulse 52 . The doctor in charge men. tions that the curious point about the case was that " the pulse continued to get slower as the temperature got higher." The case, however, recovered.

Another case of remittent fever was diagnosed which ended fatally; temperature, $105^{\circ}$; jaundice; great weakness; black motion; anorexia; delirium; patient then slowly rallied; this was followed by a relapse, coma, and death.

In this year there were several other very suspicious coses.

In 1901 a series of fatal caser, diagnosed as " remittent fever," occurred one after the other in which there were characteristic symptoms: jaundice; delirium, great weakness and coma; in one cese the romit contained bloody matter; in 1902 a case, diagnosed as " pernicious malaria," occurred and ended fatally; temperature, $103^{\circ}$; pulse, 80 ; intense gastric symptoms; black vomit; delirium ; haemorrhage from the month; skin and conjunctivae yellow; the physician notes that there was no black water and that the pulse-rate was not in proportion to the temperature.

Several other fatal cases also occurred in March and June, 1902 ; in one the diagnosis of " continued fever" was made. In this case there was black vomit and black motions.

In another case a diagnosis of "hyperpyrexial fever" was made. The skin and conjunctivae were yellow, and the post-mortem examination showed the liver yellow, the mucons membrane of stomach and intestines dotted over with fine submucous haemorrbages.

Another case was diagnosed as " remittent fever." No parasites were, however, found in the blood. Vomiting was persistent; delirium, skin yellow, melaena. Postmortem examination showed stomach and intestines intensely congested.

In another case a diagnosis of "malarial fever" was made; temperature $1082^{\circ}$, and it was noted that the pulse was very slow in comparison with the temperature. There was persistent black vomiting, melaena, albuminous 
urine, conjunctiva and skin yellow. Post-mortem examination showed intense congestion of the stomach and kidneys. Then in July of the same year the doctor's suspicions were aroused, and he had no longer any hesitation in diagnosing "yellow fever," and two fatal cases are recorded.

It is, therefore, exceedingly probable that the other cases also were yellow fever.

In the commencement of 1903, Dr. Rome Hall diagnosed a case of yellow fever, and he records minutely the sym. ptoms. He states that he first considered the case to be one of blackwater, but the presence of albumen in the urine cast doubt upon the diagnosis. He states " that the post.mortem record appeared to be universally in favour of jellow fever." The writer then states that "yellow fever has several times appeared on the French Ivory Coast and in Senegambia. The Irory Coast is only 150 miles, or forty-eight hours, away from Cape Cosst, and that at the present time quarantine is declared against the Irory Coast." $\mathrm{He}$ then states that "the Stegomyia are swarming in the 'merchants' tanks and in the tanks of the natives."

Dr. Savage, of Cape Cosst, who saw the fatal cases of 1902-3, informs me that there was no question about the diagnosis of yellow fever.

6. ACCRA.

Extracts from Casebooks.

Case A. J. S.-A new arrival. History of being bitten at Winnebah. Arrived in Accra, April, 1904.

April 19th. Patient felt unwell.

April 2lst. Temperature 104. $4^{\circ}$ Pains over body

April 22nd. Temperatare $104^{\circ}$ to $105^{\circ}$. Urine scanty, albumen present.

April 23rd. Vomiting black coffee-ground material; stools tarry.

April 25th. Vomiting persistent and violent, hiccough, tarry stools, mind wandering; pulse 120 , temperature $105^{\circ}$; coma followed by death. The medical officer regarded the disease as malaria].

Case R.-April, 1899. Notes very meagre, but the diagnosis of yellow fever was made. The symptoms of black vomit, yellow blotchy skin, and intense headache were present. Tem. perature $105^{\circ}$. On the other hand, there was no albuminuris.

Case A. W.-Patient died. Diagnosis: Subscute rhenmetism June, 1905. The symptoms were pains in joints, temperstur. $1024^{\circ}$ os urine 102. Later on, vomitin wandering, pulse weakened, coma, and death. Post-mortem wand examinstion showed deeply-congested kidnoys, and the note is made that immediately aiter death the body assumed a intensely yellow colour. This is a sign which, in $\mathrm{my}$ opinion, is extremely characteristic of yellow fever.

Case -.-Merchant, July, 1905. Diagnosis: "Bilions remit tent fever." The symptoms on July 19th were intense headache, temperature $101.8^{\circ}$, later in day $104^{\circ}$; albuminuria quinine little effect upon the temperature; vomiting becem persistent and prtient became drowsy, urine much diminished death on the 24th. Post-mortem examination showed enlarged liver (colour not stated) and deeply congested kidneys.

Case Rev. - - February, 1906. Diagnosis: "Remittent fever" 8ymptoms, Fubrory lo to $104^{\circ}$ sestrio irritebility February 4th commenced to have black vomit (coffee-ground material), collapse, death.

\section{Tarquar District.}

(Mantrain 1902, and Saw Mills 1910.)

In 1902, 8 men out of a staff of 14 died within about three weeks of one another. The doctor in charge also died; the others stampeded.

In a report which was sent from Tarquah on June 14tb, 1903, to the principal medical officer 'at Accra, the follow. ing statement is made: "I am informed that death in several cases occurred from hyperpyrexia, and that the administration of quinine, even in hypodermic injections in large doses, failed to reduce the temperature In four of the cases death took place four days after the onset of the illness. Dr. MacDonald examined his own blood during his illness, and, it is stated, found the malarial parasites.

The writer formed the opinion that the disease was "pernicious malaria with hyperpyrexia," and he notes that no mosquito nets were used, with two exceptions.

In this year (1910) a case of genuine yellow fever has occurred at Saw Mills, a small camp close to Tarquah, and $I \mathrm{am}$ therefore of opinion that it is not unressonable to suppose that the fatal epidemic of Mantrain was genuine yellow fever, especially in view of the fact of the enormous numbers of Stegomyia.
Conchusions.

I am convinced from the preceding examination of the casebooks that there were many more cases of mild yellow fever which were diagnosed as "remittent fever"; it was only when a case died, and when black vomit, slow palse, and albuminuria became marked features that the suspicions of the doctors in charge were aroused.

The mild cases passed unrecognized.

If additional proof were wanting to demonstrate the essentially endemic character of yellow fever in West Africa, it is furnished by the history and progress of the outbreak of yellow fever in the year 1910 on the Gold Cosst.

In the first place, yellow fever broke out at three distinct points-Secondee, Saw Mills, and Axim. In the second place, it shows the difficulty which the medical officer had at first in deciding whether he was face to face with yellow fever or not.

Little time was, however, lost in arriving at a final diagnosis. I am convinced from analysis of many bospital casebooks that in every probability a similar difficalty has presented itself to medical officers in the past apon many occasions, and that medical officers have refrained from giving the more serious, or, as it has been termed, " alarmist" diagnosis of yellow fever. In support of this contention, the following memorandum is of the greatest interest :

Outbreak of Yellow Fever at Secondee, 1910. The Colonial Hospital, Secondee, May 9th, 1910

I have the honour to report that recently there have been three cases of fever here, two of which came from the same bungalow, namely, Mr. and Mrs. C., and more recently Mr. W., Supervisor of Customs, that present unusual sy mptoms. Mrs. C. was removed into hospital with a temperature of $105^{\circ}$ persistent vomiting, and severe headache. She later became intensely jaundiced, but eventually made a good recovery, and has proceeded to England.

Fifteen days later Mr. C. was removed to hospital with a temperature of $103^{\circ}$, intense headache, diarrhoea, injected eyes. He suddenly collapsed and died three days later.

Mr. W. got a sudden attack of vomiting, with a temperature of $103.6^{\circ}$ at night. He now has some diarrhoes and his eyes are injected ; jaundice seems coming on. I have treated each case With intramuscular injection of quinine until cinchonized. The first case had no albuminuria; in the second I was unable to procure a specimen, as he could only micturate when defaecating. Up to the present I have only been able to procure two drachms of Mr. W.'s uri

with nitric acid (in the cold). These cases show a remarkable likeness to a series of cases in Accra, when I was there in 1905, all of which were fatal. I mentioned two cases to Dr. Tweedy when he was here on his way to Tamele, who told me that he had met with similar in Cape Coast; also I had discussed them with Dr. Slack. Without wishing to cause unnecessary alarm, I much fear yellow fever may be present here; and, beyond Drs. Slack and Tweedy, the only other person I have mentioned the matter to is the Acting Provincial Commissioner, Mr. Furley.

$$
\text { C. H. D. RaLPh. }
$$

The outbreak of yellow fever which took place in Sekondi this year (1910) differs in no essential respect from all previous ones in West Africa, or in the other parts of the tropical world. It is a matter for congratulation, however, that this disease was early recognized, and that the medical authority of the colony did not lose a day in taking preventive messures.

The outbreak, which started in March and ended in June, was a comparatively small on $\theta-$ about 13 car $\theta^{2}$; but as in all these outbreaks, so here it is more than probable that.there were other mild cases which were not diagnosed until the severe cases drew attention to the natore of the disesse-there were 10 cases amongst the white population and 3 amonget the native. The native population is large, and the white comparatively very amall (aboot 120). Therefore, as in all previous opidemics, the comparative percentage mortality amongst the whites was very much greater than amonget the natives; in fact there is no com. parison. Of the whites who were attacked, it is sig. nificant that they had been in Sekondi for periods varying from a fow days to a few months immediately prior to the outbreak.

The mortality in proportion to the number of cases notified was very high. All the cases proved fatal with one exception. The high mortality-rate is of common occurrence in countries where the medical anthorities are not suspecting yellow fever. 
The chief symptoms recorded are typical of yellow fever-namely, violent headache, yellow sclerae, jaundice or sudden turning yellow immediately after death, albuminuria, suppression of urine, delirium, Fagot's sign, black or black speckled vomit, coma. Where quinine was administered it did not appear to have any effect.

Post.mortem examinations showed boxwood liver, congested kidneys, stomach, and intestines, otherwise organs normal.

In the opinion of the senior sanitary officer, Dr. Rice, and of the acting principal medical officer, and also of the other medical officers who were associated with them in the investigation of the 1910 outbreak of yellow fever in Sekondi, the disease was of endemic origin. The fol. lowing are Dr. Rice's conclusions, and with them I agree after examination of all the circumstances on the spot :

"That yellow fever had previously broken out in the Gold Coast is well shown in the extract which the acting principal medical officer has furnished from the annual reports:

"I am a comparatively recent importation to the Gold Coast, and hence am not in a position to state what were the reasons which led the anthorities to call this disease for so many years by another name. A study of the casebooks from the various parts of the Gold Coast leave upon one's mind the impression that in many instances Europeans who have been returned as having died of malignant malaria have really died of yellow fever. Sometimes the medical officers have discussed the possibility of certain cases being yellow fever, and in other instances they have called it so, but in the annusl returns this diserse has uspally been conspicuous by its absence, and apparently, whether by accident or design, it had never been given official recognition.

"In reply to telegrams from head quarters as to the source of infection, I replied that I considered yellow fever to be endemic infection, I replied that I considered yellow fever to be endemic that opinion. There is no other hypothesis that to my mind can explain this and previous outbreaks. The precise condican explain this and previous outbreaks. The precise condithe non-immune white population are as yet unknown, but two conditions are always present when non-immunes are attacked, namely :

1. They live in native towns unsegregated from natives.

2. Under conditions which favour the breeding of the enormous numbers of Stegomyia.

“Dr. W. C. Gorgas makes an interesting statement on this subject in the Proceedings of the Cenal Zone Medicsl Association, 1908, namely : 'That a certain proportion of Stegomyia must be present in a locality for the spread of yellow fever.'

"It is castomary when an outbreak of yellow fever occurs to look for the ship that is always supposed to have brought the infection, in spite of the fact that to bring yellow fever to West Africa is equivalent to carrying coals to Newcastle.

"Two ships, the barques Montgomery and Cosmos, had brought cargoes to the port from America. The Montgomery. from Gult Port, Mississippi, arrived in Sekondi on January 17th, and left on March 7th. The voyage lasted seventy-five days, and the ship had a clean bill of health.

"The Cosmos, from Mobile, U.S.A., arrived at Sekondi on March 5th and left on April 10th, having been forty-five days on the voyage with a clean bill of health; so these ships may be regarded without suspicion."

Extracts frou the Annual Medical and Sanitary Report, 1895, Gold Coast Colony

General Health of the Colony:

"The general health of the colony was extremely bad during the period, the endemic fever assuming a pseudoepidemic form of a malignant type closely approaching in its clinical manifestations the vomito negro or yellow fever of the West Indies. The death.rate was enormous among Europeans, and the excitement induced thereby amounted almost to a panic and served to intensify the fatal tendencies of the prevailing fever in the latter part of the year."

"At the beginning of the month the general health of the town of Accra was bad, and some cases of the malignant type of fever, which during the first six months of the year prevailed on other parts of the cosst, appeared. Three deaths occurred from it amongst the officials of the African Direct Telegraph Company.

"Cape Coast.-During the first quarter the health of the European residents was extremely bad, and judging from the death-rate worse than it has been for some years. The prevalent diseases were remittent fever and diarrhoes. The former seems to have been of a very pernicious nature with a tendency to hyperpyrexia, suppression of urine, and amaurosis (Dr. Lyons). Four deaths occurred among the non-official Earopeans. During the second period the same condition of things persisted and the mortality was great; among officials two died and among non. officials six.
"Elmina.-The first quarter was marked by an unusual prevalence of malarial fever. Out of a grand total of ten. officials, eight suffered from attacks of fever, more or less violent, and of these three died and two were invalided. The non-official Europeans did not suffer so severely; out of a grand total of fourteen, one was invalided and died three days later at sea. The prominent features of the various fatal cases were blood destruction, suppression of urine, hyperpyrexia, and heart failure (Dr. Elliott). During the second quarter the unhealthiness which characterized the previous quarter was continued into the early part of May, when the onset of the wet and cold season. inaugurated a general change for the better.

"Saltpond.-In 1895 I was stationed for some time in Saltpond, during which period an outbreak of a very malignant type occurred amongst the limited European community. Amongst the cases were Father Riche, of the Catholic Mission; Mr. Trigg, of the Public Works Department; and Mr. Moran, a trader, and another merchant. One of these cases, Mr. Moran, recovered. The cases presented the features of rapid onset, high fever, which gradually subsided; jaundice and albuminaria in the three fatal cases, black vomit, suppression of urine, coma with convulsions and death, and at no time was haemoglobinuric urine passed in any case. A prominent fact which lasted for ever in my memory was the existence of a pecaliarly offenisive odour and the passage of peculiar tarry motions, the immediate circumference of which in a bedpan or chamber-pot presented a look of altered blood. All these fatal cases presented a peculiar delirious restlessness before absolute coma set in; although I was inclined to regard these as cases of yellow fever, $I$ was in possession of such information that $I$ knew such a declaration would be useless on my part; and in this connexion $I$ invite attention to paragraphs 12, 14, and 31 of the Annual Medical Report for the year 1895. Mr. Trigg lived in hired quarters in a native house, and the other Europeans lived in the town. The second Catholic Father was. invalided very soon after the death of Father Riche. I closed their house and condemned it. Some time after, when Bishop Albert and Father Wade arrived in Saltpond, I did not allow them to occupy the quarters, and told them what I thought the cause of the sickness was. At this time the mosquitos were plentiful at Saltpond in the native quarters, but I was not able to identify species."

"In the case of Mr. Trigg, I recollect wishing to try pilocarpine, owing to the suppression and to the fact that the skin remained dry. I also recollect improvising a vapour. bath in the hope of starting diaphoresis."

"There had been much sickness and mortality prior to this at Elmina and Cape Coast, and my leave was twico put off owing to the death of the medical officer deputed to relieve me. One, Dr. Lyons, being invalided and dying. Soon atter the other, Dr. Conran, died at Cape Coast. At this time much difference of opinion existed as regards the sickness, bat as far as my recollection goes the majority of the medical officers who saw cases believed they were dealing with yellow fever, and I heard that Drs. Lyons and Conran had succumbed to this disease."

Saltpond-First Quarter: The general health of the Europeans was most unsatisfactory, the prevalent diseases being remittent and intermittent fevers and dysentery. One official died from remittent fever complicated with suppression of urine (Mr. Trigg).

Extract from Report for 1896.

"The general health of the colony during the year under review shows little or no improvement on that of the previous year. This year there were amongst the Earopean popalation 11 deaths of officials and 30 non. officials, as against 15 and 23 respectively during 1895; the number invalided being 23 officials and 35 non-officials, against 26 and 32 in 1895 . This high rate is to be attributed to the fact that the epidemic of the malignant type of fever which prevailed during the last half of 1895 con. tinued during the first four months of this year, the period during which the greater number of deaths occurred.

"In Accra there was a good deal of sickness during the firgt half of the jear, but the last half was exceptionally healthy, more especially amongst the Europesn officials, this, no doubt, being due to the fact that the majority now live outside and at a considerable distance from the native. town." 
Extract from Report for $189 \%$.

"During the second quarter of the year Cape Cosst and Saltpond suffered from an outbreak of fever affecting, so far as I am aware, Europeans only, of the same nature as that which scourged Flmina and Cape Cosst early in the year 1895, and which later in the year appeared in Accra, to which the Chief Medical Officer alladed in paragraph 1 , report for 1895."

Health of Europeans at the Various Stations.

"Saltpond.-No deaths among officia]s. There were 6 deaths among non-officials, equal to a ratio of 67.4 of the total strength of Europeans in the station for the pear. No officials were invalided, bnt 3 non-officials were. As regards the causes of deathed, but 3 non-offials were. As regards the causes of Two were acuts nephritis, complicating malsrial fever, and 3 Two were acuts nephritis, complicating malarial fever, and 3 were cases presenting the classical symptoms of yellow fever. The health of the officials was good, that of the non-officials exceedingly bad. The non-official Europeans-that is, the agents of the European mercentile firms--live in houses which itnated at some distance from the lagoon and close to the beach. This is sufficient to account for the immunity enjoyed by the officials, whilst the European employees of the mercantile firms were suffering from all the varieties of fever that are met with on the cosst.

"Cape Coast. - There were 12 deaths smong non-officials, equal to a rate of 50 per 1,000; there were no desths among the to a rate of 50 per 1,000; there were no deaths among the officials. Causes of death were chie

"A. Swanzy died at Accra 25th April, 1904, case being clinically similar to yellow fever. He was nursed by Miss Fraser, who went on leave 27th June, died on 3rd July at sea; symptoms alleged to be like yellow fever.'

Note Furnished by Dr. Garland, Acting P.M.O

"I concur with the opinion of Sir Rubert Boyce that yellow fever existed for a considerable time, and was not officially recognized. However, there were occasions in 1897 and 1895, and subsequently, when many of the medical officers of this colony openly stated that they were convinced that they were dealing with this disesse, and that the matter was one actually under controversy is proved by the following extracts by chief medical officer from the medicel report for 1895 :

"Three cases in Accra occurred in one house. During this year (1895) I had 4 cases of yellow fever at Saltpond, 3 of whom died. I wrote to some of my colleagues at Cape Coast, as I know that determination had been shown in favour of the disease being declared a non-infectious bilious remittent fever. I only learnt that more than one of the members of our staff considered they were dealing with yellow fever, but that the diagnosis would not be accepted.

"I am inclined to believe that this outbreak originated at Elmina in 1894, where several Europeans died, and which had previously borne the reputation of being a most healthy station. After a considerable lapse of time an outbreak of a fatal type of fever occurred at Accra in 1896, and I understand there was a severe outbreak at Little Pope some time after this, but there is no opportunity of arriving at the facts with regard to the latter."

In the year 1897 a case of yellow fever was officially returned by the medical officer at Cape Coast.

In the year 1897 a series of deaths occurred at Saltpon and Cape Coast, and the disease there presented the clinical manifestations of yellow fever.

In 1898,4 deaths occurred in the first six months amongst the Earopeans at Saltpond, and were classed as pernicious remittent fever.

In 1902. 2 cases of yellow fever were recorded at Cape Cosst by the late Dr. W. Marray.

In 1903 a highly suspicious outbreak occurred at Mantrain and ended in six deaths, including the doctor, whose death unfortunately precluded the possibility of any medical history being rendered.

Sabsequent to this the only occrsion on which cases presented a suspicious nature was in 1904, when Mr. A. J. Swanzy died after a fow days' illness, having presented the clinical symptoms of this disesse.

In June, 1905, Mr. Wrenn was admitted, and died within a few days after showing many of the symptoms of this disesse.

Mr. Lulwer died in the bospital on July 24th after displaying many of the symptoms of yellow fever.

In February, 1906, Mr. Jubb, a Wesleyan missionary, died ; the symptoms pointed to yellow fever.
On March 14th, 1906, a Earopean clerk named Bailey died from fever showing symptoms of yellow fever.

Elliott, W. M.: Yellow Fever in West Africe, Journal of Tropica

Medicine, July, 1899 .
Browne, B. O.: A Case of Yellow Fever at Baltpond, Gold Coast. Journal of Tropical Medicine, 190

The Annual Medical and Sanitary Beports of the Gold Coast.

The Hospitai Casebook

he Qua le, James:

Aractical Medico-historical Account of the Western (1831.

Roport on Cape Coast.

Medical Reports of Troops serving upon the Gold Coast. Parliamentary Return No. 544, July. 1864

Mortality of Troops at Cape Cosst. Return No. 393, June 1864.

Mortality of Troops a Cose Cobruary, 1882

VIII.

YELLOW FEVER ON THE IVORY COAST.

From 1899 to 1905 this colony ahows a practically unbroken record of genuine malignant yellow fever. So bad had it become at one time that it was seriously proposed to abandon Grand Bassam, and, according to consular and medical reports, the greatest hindrance to commercial advance in the past has been yellow fever.

In 1899-1900 there was a very severe epidemic.

In 1903, during a period of four months, no steamers entered the port and all trade was at a standstill. In 1904 the disease was again prominent, and the port was again stated to be infected in 1905. In fact, from 1900 to 1905 a year has not passed without the report of cases, and Gazette quarantine notices have appeared in regular succession. During one of the epidemics 50 per cent. of the native population left Bassam. In 1903 the European population was about 60 , and the death-rate amongst these was 50 per cent.

In recent years drainage and specific antimosquito pre. cautionary measures bave been taken, and have replaced the old-time process of disinfection, and the burning of houses. It is to the ewakening up to the importance of specific anti.Stegomyia measures on the Ivory Coast and in Senegal, and in Togoland, that must be ascribed the immunity from yellow fever which these colonies bave experienced since 1905

BIBLIOGRAPHY.

Armstrong. J. P.: Consular Report on the Ivory Coast; Foreign Office, 1905. Kermorgant, A.: Maladies epidémiques qui ont regnè dans les
colonies françaises, 19c0, 1902, 1905, etc.; Annales d'hygiène et de médecine coloniale.

IX.

YELLOW FEVER IN TOGOLAND.

The German colony of Togoland since it has been opened up to commercial enterprise has been the geat of frequent outbreaks of yellow fever. Thas in 1896, 40 cases. were reported in Klein Popo.

After this period there appears a lull, that is to say, there was no obvious outbreak until 1905 when some cases were recorded at Anecho and Lomé. In 1906, 5 deatbs were also reported at Lomé and 1 case at Wydah. Krueger states that 30 cases occurred in Togoland from April to May, 1906. As the symptomatology and post-mortem examinations of many cases are given, there is no donbt of the identity of the disease. According to the official Gazettes, quarantive was declared against Togoland and Lomé on April 22nd, 1905; Agone and Grand Popo in May, 1905; and against all ports in Togoland, Jone, 1906.

Dr. Otto was strongly of opinion that the disease was. endemic and that the virus had been kept up by mild cases and recurrences. Those who have studied yellow fever in recent years regard this as the most rational $\in \mathbb{X}$. planation of outbreaks or sporadic cases of yellow fever.

Otto also draws attention to the fact that many of the cases of yellow fever were disgnosed as " pernicions fever," with "inflammation of the kidney," "febris malaria con. tinua perniciosa nephritica," "fever and heart dieease," etc. Thus, as in British Colonies so in the German, tbere can be no question that yellow fever has passed unnoticed under a great variety of names. Probably no diseace bas been mistaken for so many other diseases. In my opinion this has in large measure arisen from the universal reluc. tance to admit the existence of the presexce of yellow fever in any colony. No doubt onmmercial interest is 
the real cause. There were, however, excusable reasons, such as the lack of any microscopic test as in malaria, and the fact that a large proportion of cases bear a consider. able general resemblance to malaria. It is for these reasons that the best gaide to diagnosis in parts of the world where undoubted large outbreaks of the disease have occurred, is the presence of the Stegomyia in abandance. This is the case in German, as well as in the British and French West African colonies.

Vigorous anti-stagnant water ordinances have been introduced and enforced in Togoland.

\section{$x$.}

\section{YELLOW FEVER IN DAHOMEY.}

Within recent years Dahomey has been the seat of numerous recorded outbreaks. In 1905 cases occurred at Lomé and at Agone, where several deaths took place.

In 1906 an outbreak occurred at Grand Popo In the same year yellow fever was present in Porto Novo and Koonu, and 11 deaths are said to have taken place.

It is verg generally recogaized amongst merchants that the coast and river towns in Dahomey and Togoland are very liable to yellow fever.

Considering that these towns are close to Lagos, it would be excuedingly strange if Lagos should have been free from yellow fever in this period; even admitting that yellow fever was not endemic in that city, it was obviously liable to be imported at any time.

BIBLIOGRAPHY.
Otto: Ueber Gelbfieber in Afrika, Archiv f. Schiffs $u$. Tropen Hygiene, 1907 .
Krueger : Die Gelbfieber Erkrankungen in Togo, Archivf. Schiffs $u$. Tropen Hygiene, 1907.

\section{SUMMARY.}

I think I have brought forward sufficient eviderce, based upon accurate records, clinical and histurical, written by men of admitted ability and experience in yellow fever, to conclasively prove that yellow fever has been of far more frequent occarrence than is usually supposed on the West Coast. That in fact it has appeared annually over a very large namber of years, practically, as my tigures show, for the last one hundred years.

A few gaps of a few. vears have occurred, such as between 1852 and 1858,1868 and 1872, 1873 and 1878, 1878 and 1883,1884 and 1890

Bat from 1890 to the present date, I am of opinion, from the data which I have examined, that there is an unbroken line.

During the whole hundred years there is no large interval which would make it ressonable to suppose that yellow tever had completely died out on the Coast.

In my opinion this evidence is so strong that we are obliged to assume that the disease is endemic upon the West African Coast for at least the last hundred years. The question now therefore arises, By whom has the virus been kept up?

In the first place, we know positively that the transmitting agent, the Stegomyia, is present in overwhelming quantity. It only remains to prove how a continuous source of infection has been maintained.

To those who would adopt the theory of importation, it would mean a continuous importation from, say, the West Indies, Central or Suath America, and there is no history of such importation. Therefore, in my opivion, the most ressonahle explanation is the one which has proved correct in the West Indies, Central and South America, and is adopted by the most recent English, French, and German investigators in yellow fever-namely, that the disease exists amongst the natires in a mild form; in other words, that it is endemic.

A little consideration will show that the whites havenot been the source of the continuous infection for the resson that the total number of whites on the whole West African Coast has never been large enough to admit of continuous keeping up of the virus; the whites are in the very small minority. Therefore, precisely as in the case of the sister disease, malaria, the continuous or endemic source of infection is the comparatively dense native popalation of the West Cosst.

The evidence which I have brought forward also conclnsively points, both in Englisb, French, and German colonies, to a vast amount of mistaken diagnosis. Yellow ferer was not suspected in its mild form, and it was not found out; it was only discovered when fatal cases made their appearance, and, as my evidence showe, these cases were as often as not mistaken for other diseases. These same mistakes in diagnosis have occurred over and over again in yellow.fever countries, especially in the commencement.

I therefore conclade from the evidence that a com. paratively large number of deaths and mild cases have occurred from yellow fever in the past, and which have been attributed to malaria-chiefly the "bilious remittent fever." Most authurities upon yellow fever are agreed that in a very large number of ins tances "bllious remittent fever" is another name for yellow fever.

It must be recollected that it is only last year that effective sulphur fumigation of the infected Stegomyia has been attempted on the West Coast after ontbreaks.

Therefore, infected Stegomyia were left in the past to live on and to carry infection into a sacceeding year. Finally :

1. The historical record of outbreaks and sporadic cases, as recorded above ;

2. Mistaken diagnosis;

3. The absence of any destruction of infected Stegomyia in the past; and

4. The comparative immunity of the native,

is evidence over whelmingly in favour of the disesse being endernic on the Coast, and of its having been repeatedly mistaken for other diseases, or entirely overlooked, and of its being kept up in a mild form by the natives, just as formerly in Caba, Rio, and the West Indies.

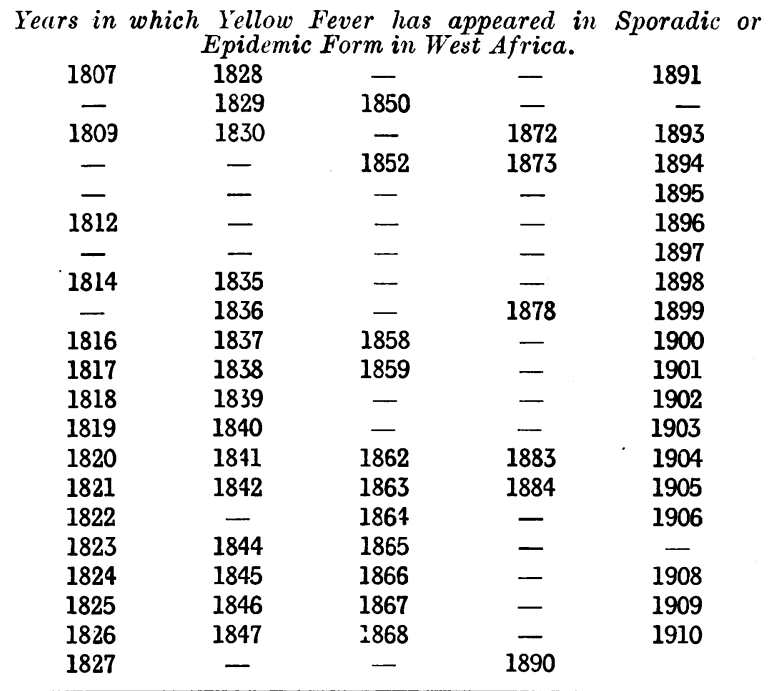

\section{Atemuranda : \\ MEDICAL, SURGICAL, OBSTETRICAL.}

\section{THE IPECACUANHA TREATMENT OF DYSENTERY} AND HEPATITIS.

The paragraph in the British Medical Journal of December 31st, 1910 (page 2039), on the discuesion in the medical section of the Asiatic Society of Bengal on the treatment of dysentery and hepatitis by ipecacuanba is very interesting, more especially to those of us who have had considerable experience of the tropics.

I shall always regret that my earlier efforts at the healing of these diseases were all directed by ideas as to inefficacy of ipecacuanba. In the Indian Medical Congress held at Calcutta in 1894, irrigation of the bowels with various lotions, and the use of sulphate of magnesia, were the lines of treatment most strongly urged, and the new arrivals in India were led away from the teaching of older days.

One case which I had under my care in Kalne Mission Hospital in May, 1909, illastrates very wonderfully some points in the ipecacaanba treatment. The pationt was a Bengali Mussulman; with amoebic abscess of the liver. I excised a rib, and opened into the abscess. Then I made the experiment of employing the Sprengel pump to secure 